\title{
The Effect of a Hydrogen Peroxide Preparation with Silver Ions on the Qualitative Traits of Table Eggs and on Reducing the mycotoxin biosynthesis
}

\author{
Łukasz Tomczyk 1,*, Tomasz Szablewski ${ }^{1}$, Kinga Stuper-Szablewska ${ }^{2}$, Agata Biadała ${ }^{1}$, Piotr Konieczny ${ }^{1}$, \\ Sebastian Nowaczewski ${ }^{3}$ and Renata Cegielska-Radziejewska ${ }^{1}$ \\ 1 Department of Food Safety and Quality Management, Poznan University of Life Sciences, Wojska Polskiego \\ 31, 60-624 Poznan, Poland \\ 2 Department of Chemistry, Poznan University of Life Sciences, Wojska Polskiego 75, 60-625 Poznań, Poland \\ 3 Department of Animal Breeding and Product Quality Assessment, Poznan University of Life Sciences, Poz- \\ nan 60-637, Poland \\ * Correspondence: tomczyk@up.poznan.pl
}

Citation: Tomczyk, Ł.; Szablewski, T.; Stuper-Szablewska, K.; Biadała, A.; Konieczny, P.; Nowczewski, S.; Ce-gielska-Radziejewska, R. The Effect of a Hydrogen Peroxide Preparation with Silver Ions on the Qualitative Traits of Table Eggs and on Reducing the mycotoxin biosynthesis . Proceedings 2021, 65, x. https://doi.org/10.3390/xxxxx

Received: 27 October 2021 Accepted: 14 January 2021 Published: 14 January 2021

Publisher's Note: MDPI stays neutral with regard to jurisdictional claims in published maps and institutional affiliations.

Copyright: (c) 2021 by the authors. Submitted for possible open access publication under the terms and conditions of the Creative Commons Attribution (CC BY) license (http://creativecommons.org/licenses /by/4.0/).

\begin{abstract}
The quality and safety of raw materials and food products are inextricably linked. Table eggs are subject to special monitoring due to microbial hazards. So far bacterial hazards have mostly been monitored. However, the latest reports have pointed to a threat that has not been considered for table eggs. Microfungi can grow on the surface of eggshells and penetrate into the egg content. Therefore, it is necessary to improve the microbiological state of the eggshell surface, which will guarantee the safety of egg consumption and slow down spoilage. The aim of the study was to examine how the sanitation of eggs with a hydrogen peroxide preparation containing silver ions affected the dynamics of growth of microfungi and the biosynthesis of mycotoxins during egg storage.The research results showed that $\mathrm{H}_{2} \mathrm{O}_{2}$ with silver ions was effective against microfungi and simultaneously limited the biosynthesis of mycotoxins. The egg sanitation treatment with a solution of hydrogen peroxide and silver ions reduced the count of microfungi, which stopped growing after one week of storage. The effectiveness of much lower concentrations of the preparation against these fungi may have been caused by the content of silver ions. There was a smaller decrease in the Haugh unit value in eggs sanitised with hydrogen peroxide and silver ions in the final period of storage. This means that the eggs lost freshness less dynamically. The research results showed that the treatment of eggs with the $\mathrm{H}_{2} \mathrm{O}_{2}$ preparation with silver ions slowed down their spoilage processes and effectively reduced their content of microfungi and mycotoxins.
\end{abstract}

Keywords: silver ions; hydrogen peroxide; eggs; microfungi; mycotoxins

\section{Introduction}

The production of table eggs is increasing worldwide, including alternative systems, i.e. organic and deep-litter production systems (FAOSTAT, 2017). However, it has been proved that eggs, especially those produced in alternative systems, are likely to be microbiologically contaminated and thus they may be potentially dangerous to consumers' health (Svobodová J. 2014). So far research has focused on bacterial microflora (De Reu et al., 2006; Gantois et al., 2009; Corry, 2017). However, the latest research has also indicated the risk of the presence of microfungi and their metabolites in table eggs. Studies on the population of fungi in table eggs have shown that they may penetrate through the shell and subshell membranes into the egg content (Szablewski et al. 2010, Tomczyk et al. 2018, Tomczyk et al. 2019). Researchers have found fungi of the Alternaria, Penicillium, Chaetomium and Fusarium genera on the eggshell surface. During egg storage these fungi grow into the egg content and produce mycotoxins in the egg white. The highest diversity and 
quantity of microfungi was observed on the shells of eggs laid by hens kept in the deeplitter and free-range systems (Tomczyk et al., 2018; Tomczyk et al., 2019). Therefore, it is necessary to improve the microbiological state of the eggshell surface to ensure the safety of consumption of table eggs and slow down their spoilage.

The washing of eggs before they are offered for sale may limit microbial contamination on the eggshell surface (Hutchison et al., 2003; Yu-Chi L el. Al 2016). Other treatments such as ionising radiation (Farkas, 1998), UV radiation (Coufal et al., 2003; RodriguezRomo Yousef et al. 2005; Szablewski et al., 2010), ozonation (Davies and Breslin, 2003; Rodriguez-Romo and Yousef et al., 2005) and ultrasound treatment (Cabeza et al., 2005) may additionally reduce the count of microorganisms, including microfungi on the eggshell surface.

Hydrogen peroxide can be used as an effective alternative agent to sanitise the surface of table eggs. The antimicrobial activity of $\mathrm{H}_{2} \mathrm{O}_{2}$ is based on the oxidation of proteins. A simultaneous treatment of eggs with an $\mathrm{H}_{2} \mathrm{O}_{2}$ solution and silver ions may increase the effectiveness of sanitation and reduce the time of exposure of the preparation on the surface of eggs. The authors conducted preliminary research and found that when eggs were treated with the $\mathrm{H}_{2} \mathrm{O}_{2}$ preparation with silver ions, their microbiological purity improved. The procedure was safe and the required mechanical properties of the eggshell were maintained (Tomczyk et al. 2018). To date the mechanism of interaction of the preparation under various egg storage conditions on microfungi and the biosynthesis of mycotoxin has not been investigated. The aim of the study was to investigate the effect of egg sanitation with a hydrogen peroxide preparation containing silver ions on the dynamics of growth of microfungi and the biosynthesis of mycotoxins during egg storage.

\section{Material and methods}

\subsection{Egg collection}

The research was conducted on 290 class M eggs with an average weight of $53 \mathrm{~g}$ laid by Hy-Line White hens kept in the free-range system. The eggs were acquired in the $32^{\text {nd }}$ week of laying. An aqueous preparation containing hydrogen peroxide $(1.5 \%)$ and silver ions $(0.015 \%)$ was used for the tests. The study conducted by Tomczyk et al. (2018) proved that this concentration of the preparation did not cause an elastic deformation of eggshells. The tested preparation is commonly used in contact with food. The eggs were sanitised by being immersed in a $3 \%$ aqueous solution at $10^{\circ} \mathrm{C}$ for $5 \mathrm{~min}$. Next, they were dried at $15^{\circ} \mathrm{C}$, placed in sterile egg boxes and stored for 4 weeks at programmed humidity (35\%, $65 \%$ and $95 \%)$ and temperature $\left(8^{\circ} \mathrm{C}\right.$ and $\left.20^{\circ} \mathrm{C}\right)$. The eggs were analysed on the day they were laid and after each week of storage. Next, egg white samples were freeze-dried (FreeZone Plus, Labconco, Kansas City, MO), and the shells were dried in a laboratory dryer at $50^{\circ} \mathrm{C}$.

\subsection{ERG analysis}

The total mycobiota content was measured on the basis of ergosterol concentration (ERG). A modified ERG measurement method, described in detail by Perkowski et al. (2008), was used in the experiment. It consisted in releasing this metabolite from the biomaterial by means of microwave-assisted saponification with simultaneous extraction. HPLC with an absorbance detector at a wavelength of $\lambda=282 \mathrm{~nm}$ and an external standard was used for the ERG analysis. The ERG recovery was $97 \%$ and the detection level was $0.01 \mathrm{mg} / \mathrm{kg}$.

\subsection{Mycotoxins in egg white}

Egg white was analysed for the content of selected mycotoxins. The concentrations of the following mycotoxins were measured: type A trichothecenes, that is, scirpentriol (STO), diacetoxyscirpenol (DAS), HT-2 toxin, T-2 toxin, T-2 tetraol, T-2 triol and type B trichothecenes, that is, deoxynivalenol (DON), 3-acetyl-deoxynivalenol (3-AcDON), 15- 
acetyl-deoxynivalenol (15-AcDON), nivalenol (NIV), fusarenone X (FUS-X). Samples (10 g) were extracted with $100 \mathrm{ml}$ mixture of acetonitrile/water (82:18). The extracts were purified by means of a solid phase extraction, using columns filled with a mixture of active carbon (Draco G 60, 100 mesh), celite (Celite 545) and neutral aluminium oxide (70-230 mesh) at a weight ratio of 1:1:1. Type B trichothecenes were analysed as trimethylsilyl derivatives, using an external model. They were separated chromatographically and analysed individually by means of a gas chromatograph (Hewlett Packard 6890, Waldbronn, Germany) coupled with a mass detector (Hewlett Packard 5972 A, Waldbronn, Germany). Selected ions (SIM) were analysed in type B trichothecenes: for DON-ions 103 and 512; for 3-AcDON-ions 117 and 482; for 15-AcDON-ions 193 and 482; for FUS-X-ions 103 and 570; for NIV -ions 191 and 600. A full-range scan of masses was analysed (100-700 $\mathrm{amu}$ ) to confirm that analysed toxins were present in the samples. The mass spectrum was compared with the analogical spectrum referring to the standard. Apart from the qualitative analysis, the toxin concentrations were measured. The results were processed with the ChemStation program. Type A trichothecenes were analysed as trifluoroacetyl derivatives. The analysis consisted in searching for selected ions (SIM). The following ions were identified in type B trichothecenes: for STO-ions 456 and 555; for T-2 tetraol-ions 455 and 568; for T-2 triol-ions 455 and 569; for DAS -ions 402 and 374; for HT-2-ions 455 and 327; for T-2-ions 327 and 401. The method of analysis resulted in the following percentages of toxin recovery: STO $82 \pm 5.3 \%$; T-2 triol $79 \pm 5.1 \%$; T-2 $86 \pm 3.8 \%$; T-2 tetraol 88 $\pm 4.0 \%$; FUS-X $79 \pm 3.1 \%$; HT- $291 \pm 3.3 \%$; DON $84 \pm 3.8 \%$; $3-\mathrm{AcDON} 78 \pm 4.8 \%$; $15-\mathrm{AcDON}$ $74 \pm 2.2 \%$ and NIV $81 \pm 3.8 \%$. The limit of detection was $0.001 \mathrm{mg} / \mathrm{kg}$

\subsection{Statistical analysis}

The data were processed with STATISICA 12.0 software (Statsoft, Tulsa, OK, USA). Covariance, correlation analysis and principal component analysis were used for sample discrimination.

\section{Results}

The qualitative traits and the concentration of ERG and mycotoxins in the eggs sanitised with a hydrogen peroxide preparation containing silver ions were analysed to check whether the sanitation treatment limited the growth of microfungi and mycotoxin biosynthesis and inhibited egg spoilage processes.

\subsection{ERG in eggshell and egg white}

The analysis of the ERG content showed mycobiota neither in the shell nor in the content of freshly laid eggs. After 3 weeks of storage of the eggs which were not treated with $\mathrm{H}_{2} \mathrm{O}_{2}$ containing silver ions there was a statistically significant dynamic growth of mycobiota on the eggshell surface. The results of measurements of the ergosterol content show that it is possible to inhibit the growth of mycobiotia on the eggshell surface by sanitation, regardless of the egg storage conditions (Fig. 1).

There were no fungi found in the content of non-sanitised eggs immediately after laying. After the second week of storage there was increased production of mycotoxins (Fig. 2). Increased humidity and temperature during egg storage significantly affected the microfungal growth dynamics. The fungal growth in the content of the eggs sanitised with $\mathrm{H}_{2} \mathrm{O}_{2}$ containing silver ions was slowed down regardless of the storage conditions (Fig. 3). 


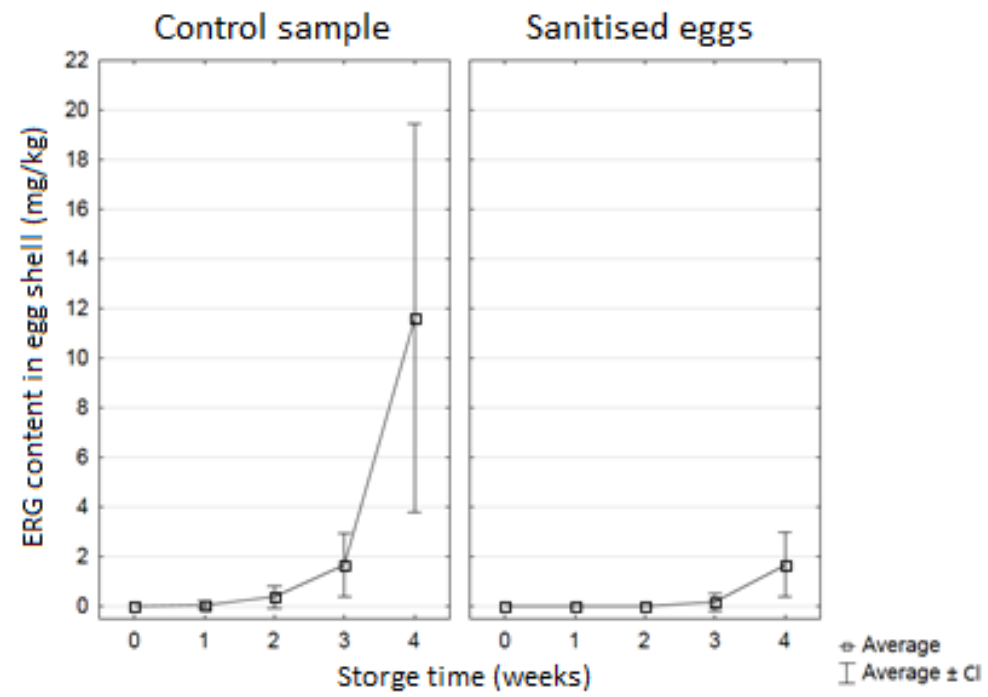

Figure 1. Variation in the ERG content in sanitised eggs regardless of their storage conditions.
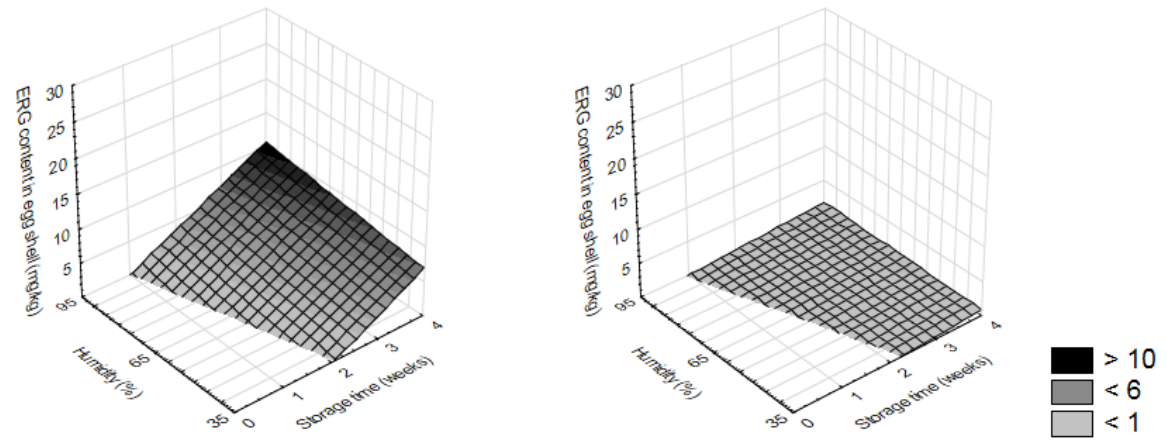

Figure 2. Variation in the ERG content in sanitised eggs during their storage at different temperatures.

A Control sample

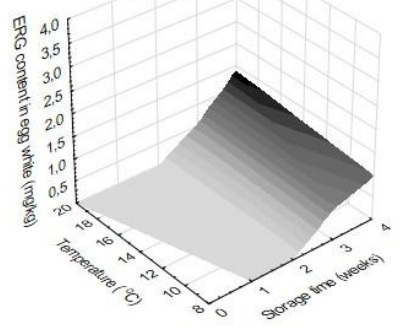

B

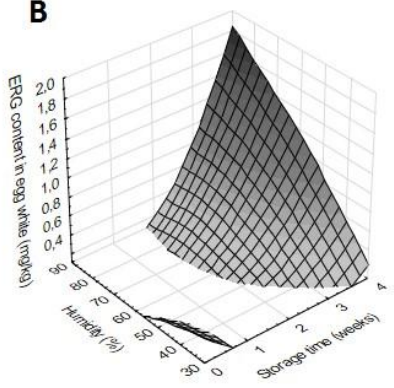

Sanitised eggs
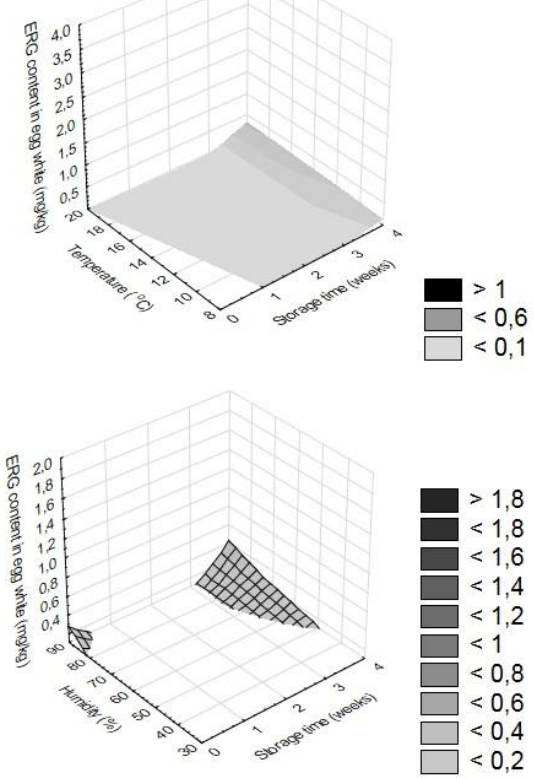

Figure 3. Variation in the ERG content in the white of eggs stored at different humidity. 


\subsection{Mycotoxins in egg white}

There were no type A or B Fusarium mycotoxins found in the content of non-sanitised eggs immediately after they had been laid and after the first week of their storage regardless of temperature and humidity (Fig. 4). After the second week of egg storage there was intensified mycotoxin production (Fig. 3), which depended significantly $(p<0.05)$ on humidity during storage. After 4 weeks of egg storage at a humidity of $95 \%$ the following concentrations of type A and B trichothecenes were measured: DON $-24 \mu \mathrm{g} / \mathrm{kg}$, FUS-X $16 \mu \mathrm{g} / \mathrm{kg}$, 3-AcDON - $8 \mu \mathrm{g} / \mathrm{kg}, 15-A c D O N-16 \mu \mathrm{g} / \mathrm{kg}$, NIV - $12 \mu \mathrm{g} / \mathrm{kg}$, Scirpentriol - 5 $\mu \mathrm{g} / \mathrm{kg}$, T-2 Tetraol $-3 \mu \mathrm{g} / \mathrm{kg}$, T-2 Triol $-2 \mu \mathrm{g} / \mathrm{kg}$, DAS $-2 \mu \mathrm{g} / \mathrm{kg}, \mathrm{HT}-2-14 \mu \mathrm{g} / \mathrm{kg}$ and T-2 $-21 \mu \mathrm{g} / \mathrm{kg}$. The presence of mycotoxins in the sanitised eggs stored at high humidity (95\%) was detected only after 3 weeks. The storage of the sanitised eggs at low humidity (35\%) totally inhibited the production of mycotoxins. The concentrations of the abovementioned mycotoxins in the sanitised eggs stored for 4 weeks at $95 \%$ humidity were as follows: 15 $\mu \mathrm{g} / \mathrm{kg}, 4 \mu \mathrm{g} / \mathrm{kg}, 2 \mu \mathrm{g} / \mathrm{kg}, 1 \mu \mathrm{g} / \mathrm{kg}, 1 \mu \mathrm{g} / \mathrm{kg}, 23 \mu \mathrm{g} / \mathrm{kg}, 0 \mu \mathrm{g} / \mathrm{kg}, 0 \mu \mathrm{g} / \mathrm{kg}, 0 \mu \mathrm{g} / \mathrm{kg}, 0 \mu \mathrm{g} / \mathrm{kg}, 5$ $\mu \mathrm{g} / \mathrm{kg}, 8 \mu \mathrm{g} / \mathrm{kg}, 13 \mu \mathrm{g} / \mathrm{kg}$.
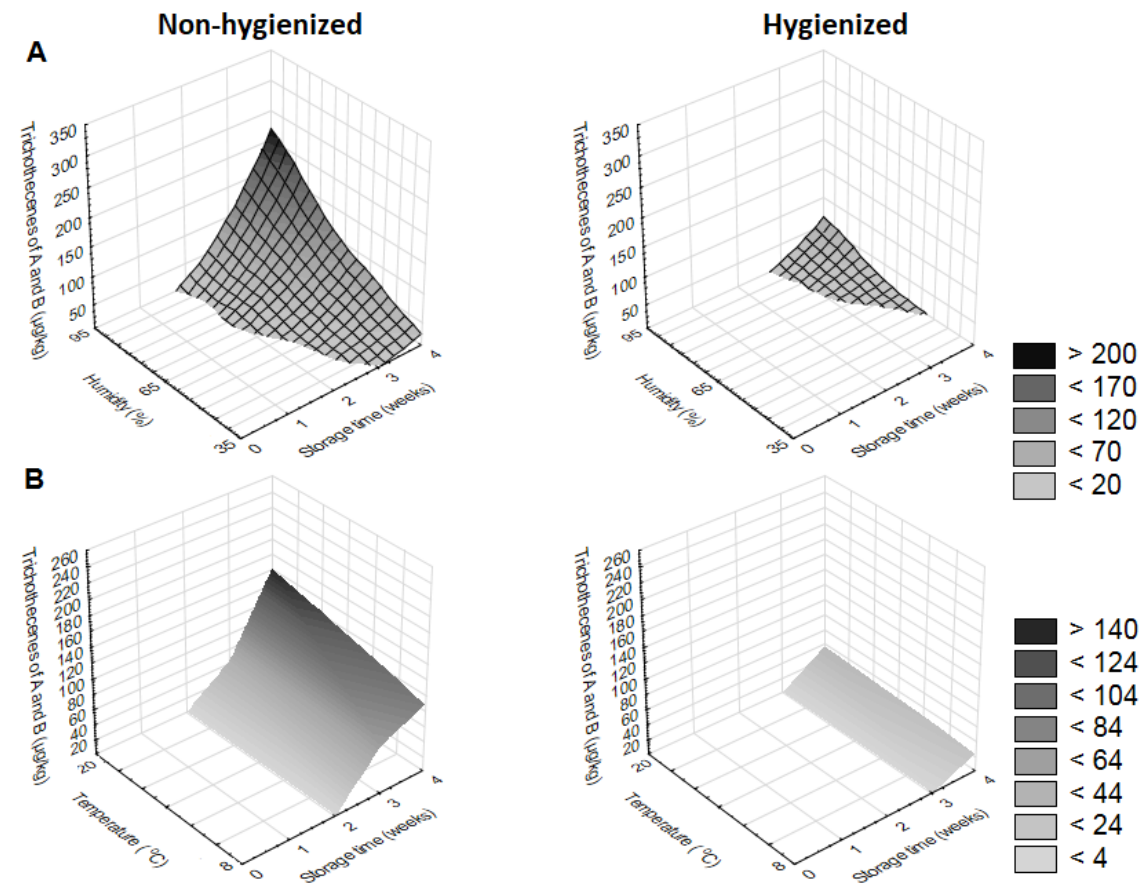

Figure 4. Variation in the content of type B trichothecenes in the eggs stored at different temperatures (B) and humidity (A).

\subsection{Analysis of factors affecting determinants under study}

Fig. 5 shows the results of principal component analysis (PCA) based on correlation. The PCA was carried out for the sanitised eggs and for the control samples stored for 4 weeks at various humidity and temperature variants. All the research results were used in the PCA. PC1 and PC2 accounted for $65.9 \%$ of the total variance. The results of the ERG and type $A$ and $B$ trichothecenes content formed separate clusters from the results of qualitative traits. The loading signs indicate that the concentration of ERG and mycotoxins were negatively correlated with the egg sanitation treatment. This means that the preparation limited the growth of microfungi and inhibited the biosynthesis of mycotoxins. 


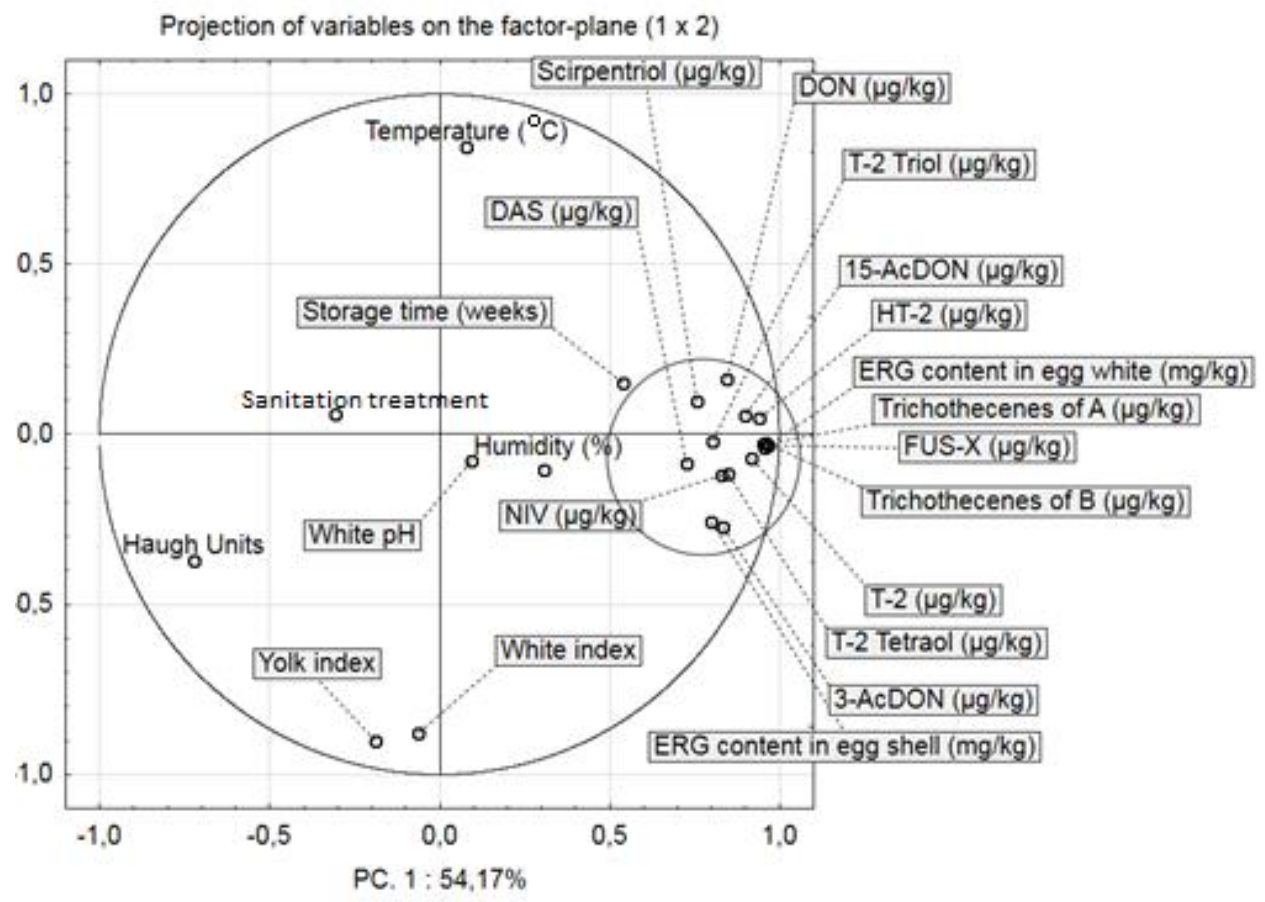

Figure 5. Principal component and loading analysis in the analysis of qualitative traits of eggs, ERG content and mycotoxin content depending on different storage conditions.

\section{Discussion}

The knowledge of the influence of the hydrogen peroxide preparation on the contamination of the eggshell surface and the content of eggs laid by hens kept in various systems in the temperate climate with mycobiota and Fusarium mycotoxins was limited. The risk of contamination is high in the hen housing systems where litter is used (Tomczyk et al. 2018; Rohweder et al. 2011). Specific storage and distribution conditions, i.e. storage time, temperature and humidity may affect the dynamics of development of mycobiota and mycotoxins in table eggs (Tomczyk et al. 2019). There is a demand for modern, inexpensive and effective antimicrobial agents that are easy to apply and do not have negative effect on the qualitative traits of eggs and consumers' health. A silver-stabilised hydrogen peroxide preparation can effectively sanitise the surface of eggshells (Tomczyk et al. 2018). Therefore, the basic scientific goal of this experiment was to examine how the $\mathrm{H}_{2} \mathrm{O}_{2}$ preparation with silver ions affected the qualitative traits of table eggs stored for 4 weeks at different humidity and temperatures and whether it limited the growth of microfungi and Fusarium mycotoxins.

The experiments confirmed the results of earlier studies, which showed that fungal biomass may penetrate into the egg content (Fig. 3). During the first week of storage the ERG concentration in the untreated eggs was $3.88 \mathrm{mg} / \mathrm{kg}$. After 4 weeks it amounted to $25.17 \mathrm{mg} / \mathrm{kg}$. In consequence, the high ERG content in the eggshell caused rapid penetration of fungal biomass into the content of eggs stored at high humidity. The $\mathrm{H}_{2} \mathrm{O}_{2}$ preparation with silver ions applied in the experiment at specific humidity and temperature successfully inhibited the growth of fungi on the eggshell surface. This effect was more pronounced in eggs stored at lower temperature and humidity. The effectiveness of the preparation may have been caused by the presence of silver ions, whose antifungal properties were proved in earlier studies (Jo et al., 2009; Kaiyuan Zheng et al., 2018). Hydrogen peroxide may increase the inactivation of microorganisms when the preparation is applied at lower concentration (Sheldon et al., 1991). 
As the duration of storage of the untreated eggs progressed, natural spoilage processes occurred. They were the most dynamic at elevated temperature and humidity. According to data published in reference publications, proteolytic bacteria are chiefly responsible for changes in the quality of eggs. However, moulds also significantly contribute to egg spoilage (Tomczyk et al., 2019). The sanitation treatment with the hydrogen peroxide preparation containing silver ions limited the growth of microfungi and thus, slowed down the egg spoilage process.

The principal component analysis showed a significant correlation between the ERG content and the concentration of mycotoxins. After two weeks of storage there was increased biosynthesis of type A and B trichothecenes in the egg white. A dynamic mycotoxin biosynthesis was observed at elevated temperature and humidity (Fig. 4). The inhibition of the growth of microfungi on the eggshell surface by the hydrogen peroxide preparation containing silver ions also resulted in trace amounts of mycotoxins in the egg white, which were found only after the third week of storage.

\section{Conclusions}

To sum up, due to the risk of contamination of eggs with microfungi and their metabolites it is necessary to search for methods reducing the initial microbial contamination of eggshell surfaces. The results of the microbiological and chemical tests showed that $\mathrm{H}_{2} \mathrm{O}_{2}$ with silver ions effectively limited the growth of microfungi and the biosynthesis of mycotoxins. The egg sanitation treatment with the hydrogen peroxide preparation containing silver ions reduced the count of microfungi and inhibited their growth after one week of egg storage. There were similar results of the study by Leina et al. (1998) concerning the effect of $\mathrm{H}_{2} \mathrm{O}_{2}$ on fungi. However, the researchers reduced the count of bacteria by using higher concentrations of hydrogen peroxide. It is likely that the preparation, which was used at much lower concentrations in our study, was effective against microfungi because it contained silver ions. Studies have shown that silver in the form of ions or nanoparticles has strong antimicrobial effect (Choi et al., 2008; Rai et al., 2008).

Acknowledgments: This research was financially supported from the Polish National Science Centre project 2012/07/D/NZ9/01004.

\section{References}

1. Cabeza, C.M., García M.M., Hoz, L. and Cambero, I. 2005. Thermoultrasonication eliminates salmonellae from intact eggshells without changing the functional properties of their components. Journal of Food Science 70:6, 292-295.

2. Choi, O., Deng, K. K., Kim, N. J., Ross, L. Jr., Surampalli, R. Y. and Hu, Z. 2008. The inhibitory effects of silver nanoparticles, silver ions, and silver chloride colloids on microbial growth. Water Research. 42(12), 3066-3074.

3. Corry, J. E. L. Microbiological analysis of red meat, poultry and eggs. In Microbiological analysis of eggs and egg products. Mead. G. C., CRC Press Cambridge England, 2007, pp. 182-187.

4. Coufal, C.D., Chavez, C., Knape, K.D. and Carey, J.B. 2003. Evaluation of a method of ultraviolet light sanitation of broiler hatching eggs. Poultry Science 82(5), 754-9.

5. Davies, R.H. and Breslin, M. 2003. Investigations into possible alternative decontamination methods for Salmonella enteritidis on the surface of table eggs. Journal of veterinary medicine. B, Infectious diseases and veterinary public health 50(1), 38-41.

6. De Reu, K., Grijspeerdt, K., Heyndrickx, M., Uyttendaele, M., Debevere J. and Herman, L. 2006. Bacterial shell contamination in the egg collection chains of different housing systems for laying hens. British Poultry Science 47(2): 163-72.

7. Eke, M.O., Olaitan, N.I. and Ochefu J.H. 2013. Effect of Storage Conditions on the Quality Attributes of Shell (Table) Eggs. Nigerian Food Journal 2, 18-24.

8. FAOSTAT. Production: Livestock Primary: Hen Eggs in Shell. 2017. Available online: http://fenixservices.fao.org/faostat/static/documents/EI/EI_e.pdf (accessed on 25.05.2020).

9. Farkas, J. 1998. Irradiation as a method for decontaminating food. A review. International Journal of Food Microbiology 44(3), 189-204.

10. Gantois, I., Ducatelle, R., Pasmans, F., Haesebrouck, F., Gast, R., Humphrey, T.J. and F. Van Immerseel. 2009. Mechanisms of egg contamination by Salmonella Enteritidis. FEMS Microbiology Reviews 33(4), 718-738.

11. Jo, Y.K., Kim, B. H. and Jung G. 2009. Antifungal activity of silver ions and nanoparticles on phytopathogenic fungi. Plant Disease 93, 1037-1043. 
12. Joseph, L.M., Koon T.T. and Man, W.S. 1998. Antifungal effects of hydrogen peroxide and peroxidase on spore germination and mycelial growth of Pseudocercospora species. Canadian Journal of Botany 76(12), 2119-2124.

13. Perkowski, J., Busko, M., Stuper, K., Kostecki, M., Matysiak, A. and Szwajkowska-Michalek, L. 2008. Concentration of ergosterol in smallgrained naturally contaminated and inoculated cereals. Biologia. 63, 542-547

14. Rodriguez-Romo, L.A. and Yousef, A.E. Inactivation of Salmonella enterica serovar Enteritidis on shell eggs by ozone and UV radiation. Journal of Food Protection 2005, 68(4), 711-717.

15. Rohweder, D., Valenta, H., Sondermann, S., Schollenberger, M., Drochner, W., Pahlow, G., Döll, S. and Dänicke S. 2011. Effect of different storage conditions on the mycotoxin contamination of Fusarium culmorum-infected and non-infected wheat straw. Mycotoxin Research 27(2), 145-153.

16. Sheldon, B.W. and Brake J. 1991. Hydrogen peroxide as an alternative hatching egg disinfectant. Poultry Science 70(5), 1092-1098.

17. Svobodová, J. and Tůmová, E.. 2014. Factors affecting microbial contamination of market eggs: a review. Scientia Agriculturae Bohemica 45 (4): 226-237.

18. Szablewski, T., Stuper, K., Cegielska-Radziejewska, R., Kijowski, J. and Perkowski, J. 2010. Ergosterol as an indicator of the presence of microscopic fungi in eggs for human consumption produced in different husbandry systems. Poultry Science 89, 2491-2493.

19. Tomczyk, Ł., Stępień, Ł., Urbaniak, M., Szablewski, T., Cegielska-Radziejewska, R. and Stuper-Szablewska K. 2018. Characterisation of the Mycobiota on the Shell Surface of Table Eggs Acquired from Different Egg-Laying Hen Breeding Systems. Toxins. 10(7), 293.

20. Tomczyk, Ł., Szablewski, T., Stuper-Szablewska, K., Nowaczewski, S. and Cegielska-Radziejewska R. 2019. The Influence of the Conditions of Acquisition and Storage of Table Eggs on Changes in Their Quality and the Presence of Mycobiota and Fusarium Mycotoxins. Poultry Science 98(7), 2964-2971.

21. Yu-Chi, L., Ter-Hsin, C., Ying-Chen, W., Yi-Chain, L. and Fa-Jui, T. 2016. Effects of egg washing and storage temperature on the quality of eggshell cuticle and eggs. Food Chemistry 211, 687-693.

22. Zheng, K., Inggrid, M., David, S., Leong, T. and Xie J. 2008. Antimicrobial silver nanomaterials. Coordination Chemistry Reviews 357, 1-17. 